\title{
Use of proton pump inhibitors and risk of hip/femur fracture: a population-based case-control study
}

\author{
S. Pouwels • A. Lalmohamed $\cdot$ P. Souverein • \\ C. Cooper • B. J. Veldt • H. G. Leufkens • A. de Boer • \\ T. van Staa $\cdot$ F. de Vries
}

Received: 24 April 2010 / Accepted: 31 May 2010 / Published online: 29 June 2010

(C) The Author(s) 2010. This article is published with open access at Springerlink.com

\begin{abstract}
Summary Previous studies evaluated the association between proton pump inhibitor (PPI) use and subsequent fracture risk, but they showed ambiguous results. Therefore, the objective was to evaluate this association in a different study population. Our findings show that there is probably no causal relationship between PPI use and hip fracture risk.
\end{abstract}

S. Pouwels $\cdot$ A. Lalmohamed $\cdot$ P. Souverein $\cdot$ H. G. Leufkens $\cdot$

A. de Boer $\cdot$ T. van Staa $\cdot$ F. de Vries $(\square)$

Division of Pharmacoepidemiology and Pharmacotherapy,

Utrecht Institute for Pharmaceutical Sciences,

Universiteit Utrecht,

P.O. Box 80082, 3508 TB Utrecht, The Netherlands

e-mail: f.devries@uu.nl

C. Cooper $\cdot$ T. van Staa $\cdot$ F. de Vries

MRC Epidemiology Resource Centre,

University of Southampton, Southampton General Hospital,

Southampton, UK

C. Cooper

Institute of Musculoskeletal Sciences, University of Oxford,

Oxford, UK

B. J. Veldt

Department of Gastroenterology and Hepatology,

Erasmus MC University Medical Center,

Rotterdam, Netherlands

T. van Staa $\cdot$ F. de Vries

General Practice Research Database,

Medicines and Healthcare Products Regulatory Agency,

London, UK

Present Address:

F. de Vries

Utrecht Institute for Pharmaceutical Sciences,

Universiteit Utrecht,

Sorbonnelaan 16 ,

3584 CA Utrecht, The Netherlands
Introduction Previous studies evaluated the association between PPI use and subsequent fracture risk, but they showed ambiguous results. To further test these conflicting results, the objective of this study was to evaluate the association between the use of PPIs and the risk of hip/ femur fracture in a different study population.

Methods A case-control study was conducted using data from the Dutch PHARMO record linkage system. The study population included 6,763 cases aged 18 years and older with a first hip/femur fracture during enrolment and 26,341 age-, gender- and region-matched controls.

Results Current users of PPIs had an increased risk of hip/ femur fracture yielding an adjusted odds ratio (AOR) of 1.20 (95\% CI 1.04-1.40). Fracture risk attenuated with increasing durations of use, resulting in AORs of $1.26(95 \%$ CI $0.94-1.68)$ in the first 3 months, 1.31 (95\% CI $0.97-$ 1.75 ) between 3 and 12 months, 1.18 (95\% CI 0.92-1.52) between 13 and 36 months and 1.09 (95\% CI 0.81-1.47) for use longer than 36 months.

Conclusion Our findings show that there is probably no causal relationship between PPI use and hip fracture risk. The observed association may be the result of unmeasured distortions: although current use of PPIs was associated with a 1.2-fold increased risk of hip/femur fracture, the positive association was attenuated with longer durations of continuous use. Our findings do not support that discontinuation of PPIs decreases risk of hip fracture in elderly patients.

Keywords Fracture risk $\cdot$ Histamine $\mathrm{H}_{2}$-receptor antagonist Proton pump inhibitor
Abbreviations
CI Confidence interval
H2RA Histamine $\mathrm{H}_{2}$-receptor antagonist 
ICD International Classification of Diseases

AOR Adjusted odds ratio

GPRD General Practice Research Database

PPI Proton pump inhibitor

RLS Record Linkage System

\section{Introduction}

Proton pump inhibitors (PPIs) are widely used to treat several gastrointestinal disorders, including peptic ulcer disease and gastroesophageal reflux [1]. It has been reported that use of PPIs decreases calcium absorption in the stomach $[2,3]$, which increases the risk for hip fracture [4]. Conversely, PPIs may also reduce bone resorption through proton pump inhibition of osteoclastic cells [5-7], which may decrease the risk for a hip fracture.

To further investigate the clinical importance of these opposing effects, three large epidemiological studies have been conducted, using data from the UK General Practice Research Database (GPRD), the databases of the Danish national healthcare System and the Canadian Population Health Research Data Repository. All three studies found a positive association between the use of PPIs and risk of hip fracture [8-10]. In addition, the UK and the Canadian study reported that the risk of fracture further increased with longer cumulative durations of use [8, 10]. Intriguingly, using data from the same GPRD, two other groups of researchers have reported different findings, which did not support a causal relationship between PPI use and fracture risk. In both GPRD studies, the risk of hip fracture decreased with prolonged PPI use [11, 12].

The discrepancies between the different "duration of use" analyses in the studies mentioned above are important, because "duration of use" analyses provide indirect evidence that may support a causal effect. Therefore, the objective of this study was to evaluate the association between the (duration of) use of PPIs and the risk of hip/ femur fracture in a different study population.

\section{Methods}

\section{Study design}

The Dutch PHARMO Record Linkage System (RLS) was used to conduct a case-control study. PHARMO RLS (http://www.pharmo.nl) includes the virtually complete pharmacy dispensing histories of community-dwelling residents in the Netherlands, which are linked to hospital admission records. Pharmacy data include information about the drug dispensed, the date of dispensing, the prescriber, the amount dispensed, the prescribed dosage regimen and the estimated duration of use. Hospital discharge records include detailed information on date of admission, discharge diagnoses and procedures. The version of the database used for this study, represents about $7 \%$ of the general Dutch population. Patients are included irrespective of their health insurance or socio-economic status. Moreover, validation studies have shown that the PHARMO RLS has a high level of data completeness and validity [13], especially with regards to recording of hip fractures $[14,15]$.

A case-control analysis was conducted within PHARMO RLS between January 1, 1991 and December 31, 2002. Cases were 18 years or older and sustained a hip or femur fracture during the study period. The first hospital admission date for a hip/femur fracture defined the index date. The ICD codes $820-821$ were used to identify hip/ femur fractures. Up to four control patients were matched to each case by year of birth, gender and geographical region. The selected control patients were PHARMO RLS participants without any fracture during enrolment. Controls were assigned the same index date as their matched case.

\section{Exposure assessment}

Current users of PPIs or histamine $\mathrm{H}_{2}$-receptor antagonists (H2RAs) were defined as patients who had received at least one PPI or H2RA dispensing within the 30 days before the index date. Recent, past and distant past users received their last dispensing in respectively the 31-91 days, 92-365 days or $>1$ year before the index date.

For each current user, we calculated the average daily dose by division of the cumulative dose by the treatment time, using defined daily dosages (DDD) [16]. One DDD is equivalent to $20 \mathrm{mg}$ orally administered omeprazole, $40 \mathrm{mg}$ pantoprazole, $30 \mathrm{mg}$ lansoprazole, $20 \mathrm{mg}$ rabeprazole, $30 \mathrm{mg}$ esomeprazole, $800 \mathrm{mg}$ cimetidine, $300 \mathrm{mg}$ ranitidine, $300 \mathrm{mg}$ nizatidine, $150 \mathrm{mg}$ roxatidine and $40 \mathrm{mg}$ famotidine. The expected continuous duration of PPI or H2RA use was based on the prescribed drug supply and prescribed daily dose. In case of overlap between two dispensings (i.e. a repeat dispensing filled within the duration of use for a previous dispensing), or a repeat dispensing filled within 182 days after discontinuation of the previous period, this period was then extended. In case of missing data on daily dose, the median expected duration of use for the PPI or H2RA of interest, was used. Because acid suppressants may be prescribed for the treatment of gastrointestinal side effects of oral glucocorticoids, the main analysis was stratified to concomitant use of oral glucocorticoids (i.e. a prescription in the 6 months before the index date). 
We adjusted our analyses for the use of anxiolytics/ hypnotics within 3 months before, and antacids other than PPIs or H2RAs, hormone replacement therapy, betablockers, antidiabetics, antipsychotics, antidepressants, anticonvulsants, two ore more non-steroidal anti-inflammatory drug dispensings, disease-modifying antirheumatic drugs, average daily dose of oral corticosteroids in the 6 months before the index date. Furthermore, we adjusted our analyses for a history of diseases of the oesophagus/ stomach/duodenum, diabetes mellitus, rheumatoid arthritis, inflammatory bowel disease, anaemia, mental disorders, endocrine disorders, congestive heart failure, cerebrovascular disease and chronic obstructive pulmonary disease.

Sensitivity analyses

Two sensitivity analyses were conducted. In the first sensitivity analysis, we restricted cases and controls to those who had at least 1 year of follow-up time before the index date. In the second sensitivity analysis, we did not restrict our analyses to current PPI use only: in contrast to the studies performed by Targownik et al. [10], de Vries et al. [11] and the current PHARMO study, Yang et al. [8] did not take into account the timing of PPI exposure. For example, in his study, patients who had stopped taking PPIs 10 years before the index date were considered to have the same increased risk of hip fracture as patients who were taking PPIs on the index date [8]. The underlying assumption of this study design, is that PPI-induced bone damage, is irreversible. Conversely, during the design of the current study, we assumed that bone damage caused by PPI intake probably is reversible, similar to detrimental effects on bone caused by other drugs, such as oral corticosteroids $[17,18]$. When reversibility of a side effect of a drug is assumed, the analyses should take into account the timing of exposure, which has been done in all our main analyses.

\section{Statistical analysis}

We used conditional logistic regression (SAS version 9.1.3, PHREG procedure; SAS Inc., Cary, NC, USA) to quantify the strength of the association between use of PPIs and H2RAs and risk of hip/femur fracture. Adjusted odds ratios (AORs) for hip/femur fracture were estimated by comparing PPI or H2RA use with no use. The analyses were stratified by class (PPI or H2RA), sex, continuous duration of use, average daily dose and concomitant use of oral corticosteroids. Backward elimination was used to establish the final model of confounders from the pivotal exposure analysis. In addition, smoothing spline regression plots were used to visualise the association between risk of hip/femur fracture and both timing and continuous duration of use [19].

\section{Results}

We identified 6,763 patients who sustained a hip/femur fracture and 26,341 controls (Table 1). Their mean age and gender were equally distributed among cases and controls. The average time period of prescribing data before the index date was 4.1 years.

Table 2 shows that current use of both PPIs and H2RAs was significantly associated with an increased risk of hip/ femur fracture, yielding AORs of 1.20 (95\% CI 1.04-1.40)

Table 1 Baseline characteristics of cases and controls

\begin{tabular}{|c|c|c|c|c|c|}
\hline \multirow[t]{2}{*}{ Characteristic } & \multicolumn{2}{|l|}{ Cases } & \multicolumn{2}{|l|}{ Controls } & \multirow{2}{*}{$\begin{array}{l}\text { Crude } \\
\text { OR }(95 \% \mathrm{CI})\end{array}$} \\
\hline & $n=6,763$ & $\%$ & $n=26,341$ & $\%$ & \\
\hline Mean age (years) & 75.7 & & 75.3 & & \\
\hline Number of females & 4,929 & 73 & 19,138 & 73 & \\
\hline \multicolumn{6}{|l|}{ Use 6 months before the index date } \\
\hline Proton pump inhibitors & 573 & 8 & 1,714 & 7 & $1.35(1.22-1.49)$ \\
\hline Histamine $\mathrm{H}_{2}$-receptor antagonists & 433 & 6 & 1,412 & 5 & $1.21(1.08-1.35)$ \\
\hline Other antacids & 204 & 3 & 576 & 2 & $1.41(1.20-1.66)$ \\
\hline Oral glucocorticoids & 366 & 5 & 918 & 3 & $1.59(1.40-1.80)$ \\
\hline Disease modifying antirheumatic drugs & 115 & 2 & 202 & 1 & $2.27(1.80-2.86)$ \\
\hline Two or more non-steroidal anti-inflammatory drug dispensings & 929 & 14 & 2584 & 10 & $1.46(1.35-1.59)$ \\
\hline \multicolumn{6}{|l|}{ Hospitalisation before index date } \\
\hline Diseases of the oesophagus, stomach and duodenum & 118 & 2 & 248 & 1 & $1.86(1.49-2.32)$ \\
\hline Cardiovascular disease & 359 & 5 & 1,289 & 5 & $1.10(0.98-1.25)$ \\
\hline Cerebrovascular disease & 296 & 4 & 565 & 2 & $2.12(1.84-2.45)$ \\
\hline
\end{tabular}

$O R$ odds ratio, $C I$ confidence interval 
Table 2 Use of PPIs or H2RAs and risk of hip fracture, by duration of use

\begin{tabular}{|c|c|c|c|c|c|c|}
\hline & Cases $(n=6,763)$ & $\%$ & Controls $(n=26,341)$ & $\%$ & Crude OR $(95 \% \mathrm{CI})$ & Adjusted $^{\mathrm{a}}$ OR $(95 \% \mathrm{CI})$ \\
\hline \multicolumn{7}{|l|}{ PPI use before } \\
\hline Never & 5,810 & 85.9 & 23,430 & 88.9 & 1.00 & 1.00 \\
\hline Distant past use & 305 & 4.5 & 907 & 3.4 & $1.38(1.21-1.58)$ & $1.24(1.08-1.43)$ \\
\hline Past use & 75 & 1.1 & 290 & 1.1 & $1.08(0.83-1.39)$ & $0.97(0.74-1.26)$ \\
\hline Recent use & 268 & 4.0 & 941 & 3.6 & $1.18(1.03-1.36)$ & $0.96(0.83-1.12)$ \\
\hline Current use & 305 & 4.5 & 773 & 2.9 & $1.62(1.41-1.86)^{\mathrm{b}}$ & $1.20(1.04-1.40)^{\mathrm{b}}$ \\
\hline \multicolumn{7}{|l|}{ Duration of use ${ }^{c}$} \\
\hline$\leq 3$ months & 71 & 1.0 & 177 & 0.7 & $1.63(1.24-2.15)$ & $1.26(0.94-1.68)$ \\
\hline 4-12 months & 72 & 1.1 & 165 & 0.6 & $1.79(1.36-2.38)$ & $1.31(0.97-1.75)$ \\
\hline 13-36 months & 94 & 1.4 & 251 & 1.0 & $1.55(1.22-1.97)$ & $1.18(0.92-1.52)$ \\
\hline$>36$ months & 68 & 1.0 & 180 & 0.7 & $1.54(1.16-2.05)$ & $1.09(0.81-1.47)$ \\
\hline \multicolumn{7}{|l|}{ H2RA use before } \\
\hline Never & 5,624 & 83.2 & 22,545 & 85.6 & 1.00 & 1.00 \\
\hline Distant past use & 598 & 8.8 & 2,020 & 7.7 & $1.18(1.07-1.30)$ & $1.01(0.90-1.12)$ \\
\hline Past use & 108 & 1.6 & 364 & 1.4 & $1.21(0.97-1.50)$ & $1.03(0.83-1.29)$ \\
\hline Recent use & 237 & 3.5 & 892 & 3.4 & $1.06(0.92-1.23)$ & $0.91(0.78-1.06)$ \\
\hline Current use & 196 & 2.9 & 520 & 2.0 & $1.52(1.28-1.80)^{\mathrm{d}, \mathrm{e}}$ & $1.19(1.00-1.42)^{\mathrm{d}}$ \\
\hline \multicolumn{7}{|l|}{ Duration of $u e^{c}$} \\
\hline$\leq 3$ months & 47 & 0.7 & 104 & 0.4 & $1.85(1.30-2.62)$ & $1.57(1.10-2.24)$ \\
\hline 4-12 months & 43 & 0.6 & 116 & 0.4 & $1.51(1.06-2.15)$ & $1.14(0.79-1.64)$ \\
\hline 13-36 months & 51 & 0.8 & 168 & 0.6 & $1.22(0.89-1.68)$ & $0.92(0.67-1.28)$ \\
\hline$>36$ months & 55 & 0.8 & 132 & 0.5 & $1.64(1.19-2.25)$ & $1.30(0.94-1.81)$ \\
\hline
\end{tabular}

$O R$ odds ratio, $C I$ confidence interval

${ }^{a}$ Adjusted for use of other antacids, average daily dose of oral corticosteroids, anxiolytics/hypnotics, short- or long-acting benzodiazepines, hormone replacement therapy, anticonvulsants, antipsychotics, antidepressants, beta-blockers, antidiabetics, two ore more non-steroidal anti-inflammatory drug dispensings, disease modifying antirheumatic drugs, a history of digestive system disorders, anaemia, mental disorders, cerebrovascular disease, congestive heart failure, endocrine disorders, rheumatoid arthritis, diabetes mellitus, chronic obstructive pulmonary disease and inflammatory bowel disease. Furthermore, the proton pump inhibitor (PPI) analysis was adjusted for the use of histamine $\mathrm{H}_{2}$-receptor antagonists (H2RAs) and the H2RA analysis for the use of PPIs

${ }^{\mathrm{b}}$ Wald statistic: current PPI use statistically significantly different $(P<0.05)$ from recent PPI use

${ }^{\mathrm{c}}$ Duration of use: duration of continuous use with washout periods of $\leq 3$ months

${ }^{\mathrm{d}}$ Wald statistic: current H2RA use statistically significantly different $(P<0.05)$ from recent H2RA use

${ }^{\mathrm{e}}$ Wald statistic: current H2RA use statistically significantly different $(P<0.05)$ from distant H2RA use

and 1.19 (95\% CI 1.00-1.42), respectively. After discontinuing the use of acid suppressants for 1-3 months, a rapid drop towards baseline was observed for both PPIs and H2RAs. The risk of hip/femur fracture was statistically significantly higher among current users of PPIs and H2RAs compared to recent users. This association is also presented in Fig. 1.

Table 2 also shows that longer durations of use attenuated the risk association. Current PPI users were at highest risk during the first year of continuous exposure, but this risk decreased over time. In addition, no increased risk of hip/femur fracture was observed among current users ( 8 cases and 29 exposed controls) with a duration of PPI use exceeding 7 years, yielding an AOR of $0.89(95 \%$ CI 0.34-2.01). The association between the duration of continuous PPI and H2RA use, and the risk of hip fracture is graphically illustrated in Fig. 2.
Furthermore, the risk of hip/femur fracture was highest among those current users who received the highest daily dose of PPIs. The PPI use below an average daily dose of 1.00 DDD, resulted in an AOR of 1.21 (95\% CI 0.93-1.57) as shown in Table 3. This risk declined to an AOR of 1.12 (95\% CI 0.88-1.42) among users receiving a DDD between 1.00 and 1.75 , but extended to a statistically significant increased risk among those who received more than 1.75 DDD, yielding an AOR of 1.35 (95\% CI 1.02-1.77). After comparing the results for average daily dose of PPIs with the average daily dose of H2RAs, no statistically significant differences were observed between both groups.

Table 4 shows the risk of hip fracture among current PPI users when stratifying according to concomitant use of oral glucocorticoids. Exposure to oral glucocorticoids increased fracture risk, while those who received $15 \mathrm{mg}$ prednisolone 


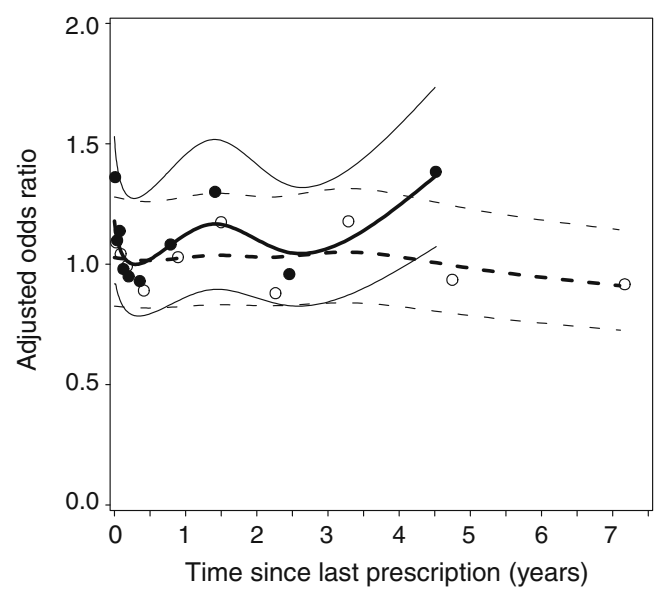

Fig. 1 Risk of hip/femur fracture and time between index date and most recent dispensing of acid suppressants. Solid lines, solid circles AORs of PPI including confidence bands; dashed lines, open circles H2RAs including confidence bands (adjusted for same confounders as listed under Table 2)

equivalent/day or more were at highest risk (AOR of 2.35 [95\% CI 1.07-5.20]).

Stratification according to sex showed that risk of fracture was statistically significantly higher among current PPI users who were men, AOR 1.57 (95\% CI 1.16-2.12), compared to women AOR $1.12(95 \%$ CI $0.94-1.32)$ with a $P$ value $<0.05$. Although not statistically significant, we observed the same trend among current H2RA users.

In the first sensitivity analysis, we restricted cases and controls to those who had at least 1 year of follow-up time before the index date. Current users of PPIs or H2RAs had the following risks of hip/femur fracture: AORs 1.25 (95\% CI 1.07-1.47) for PPI users and 1.12 (95\% CI $0.92-1.35)$ for H2RAs users. This was not different from the findings in Table 2.

In the second sensitivity analysis, we lumped current, recent and past PPI use categories, and stratified them by cumulative duration of use, similar to the methodology of Yang et al. [8]. There was still an inverse relationship between duration of PPI use and hip fracture, with a slightly decreased magnitude: AORs were 1.13 (95\% CI 1.02-1.25) for patients using PPIs up to 1 year, 1.21 (95\% CI 0.98 $1.50)$ for $1-2$ years, $1.03(95 \%$ CI $0.78-1.35)$ for $2-3$ years and 0.96 (95\% CI $0.78-1.20)$ for PPI exposure exceeding 3 years. There was no association between H2RA users and hip fracture (data not shown).

\section{Discussion}

We found that current PPI use was associated with a 1.2fold increased risk of hip/femur fracture. Higher daily dosages ( $>1.75$ DDD), male gender, and use of oral corticosteroids further increased the risk. The highest increase of risk was observed within the year after initiation of acid suppressants, and attenuated with prolonged use. This finding, does not support a causal effect of PPIs on bone, but suggests the presence of unmeasured distortion, such as selection bias and/or residual confounding.

The key finding of this study is that the increased risk of hip/ femur fracture among current acid suppressant users is probably not causal. As far as we know, PPIs and H2RAs do not increase the risk of falling. Therefore, if a causal relationship exists, fracture risk should increase only after long-term exposure (at least 6-12 months to alter bone mineral density). However, the smoothing spline regression plots (Fig. 2) did not provide evidence for a duration of use effect. Furthermore, acid suppression in the stomach caused by PPIs is significant greater and lasts longer compared with H2RAs $[1,20]$. Thus, if impaired calcium absorption caused by acid suppression is associated with an increased risk of fracture, this should be most abundant with PPI use. Nevertheless, prolonged H2RA use (instead of PPI use) of $>36$ months yielded a higher AOR of 1.30 (95\% CI $0.94-1.81)$ compared to PPI use with an AOR of 1.09 (95\% CI 0.81-1.47). These results support the alternative hypothesis that the observed association is flawed due to unknown distortion, instead of an increased fracture risk caused by impaired calcium absorption. Consequently, these results do not support the hypothesis that acid suppression is associated with an increased risk of fracture.

Clinical studies showed conflicting results regarding calcium uptake and osteoclastic pump inhibition in users of PPIs [21]. When studying calcium uptake along with a meal, Graziani et al. and Hardy et al. [3, 22] found that calcium uptake was decreased in hypochlorhydric subjects, whereas other studies did not observe any effect [23-25]. Only during fasting conditions calcium uptake was de-

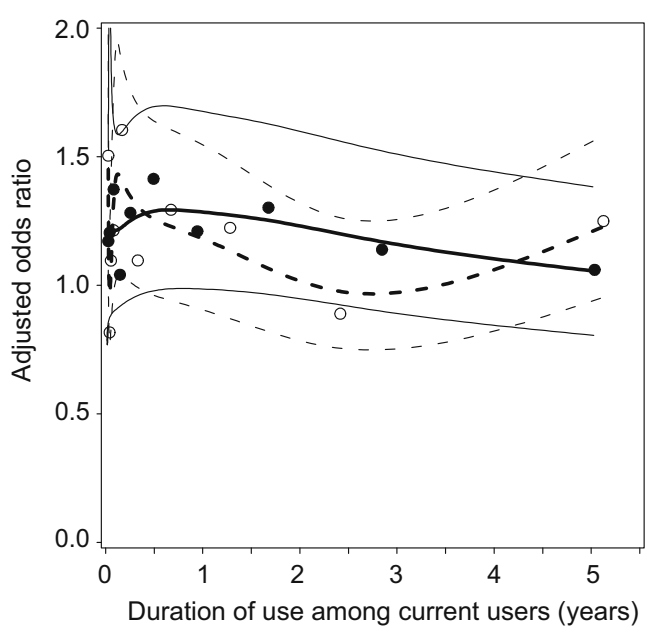

Fig. 2 Risk of hip/femur fracture and continuous duration of PPI or H2RA use among current users. Solid lines, solid circles AORs of PPI including confidence bands; dashed lines, open circles H2RAs including confidence bands (adjusted for same confounders as listed under Table 2) 
Table 3 Use of PPIs or H2RAs and risk of hip fracture, by daily dose

\begin{tabular}{lcr}
\hline Use before & $\begin{array}{l}\text { PPI } \\
\text { Adjusted }{ }^{\mathrm{a}} \text { OR (95\% CI) }\end{array}$ & $\begin{array}{l}\text { H2RA } \\
\text { Adjusted }{ }^{\mathrm{a}} \text { OR (95\% CI) }\end{array}$ \\
\hline $\begin{array}{l}\text { Never } \\
\text { Current use }\end{array}$ & 1.00 & 1.00 \\
Average daily dose, DDD & $1.20(1.04-1.40)$ & $1.19(1.00-1.42)$ \\
$\quad$ First time user & $1.29(0.79-2.09)$ & $1.40(0.78-2.51)$ \\
$<1.00$ & $1.21(0.93-1.57)$ & $0.93(0.73-1.18)^{\mathrm{b}}$ \\
$1.00-1.75$ & $1.12(0.88-1.42)$ & $1.67(1.21-2.31)^{\mathrm{b}}$ \\
$>1.75$ & $1.35(1.02-1.77)$ & $1.57(0.89-2.77)$ \\
\hline
\end{tabular}

$O R$ odds ratio, $C I$ confidence interval, $D D D$ defined daily dosage

${ }^{a}$ Adjusted for the same confounders listed in Table 2

${ }^{\mathrm{b}}$ Wald statistic: the risk of hip fracture is statistically significantly lower among current H2RA users with $<1.00$ DDD compared with current H2RA users with 1.00-1.75 DDD $(P<0.05)$

creased among patients using PPIs [2, 22] and among achlorhydric patients $[23,26]$. Furthermore, some in vitro $[6,7]$ and in vivo [5] studies suggested that PPIs could inhibit the osteoclastic proton pump and thereby reduce bone resorption. Conversely, short-term omeprazole treatment did not alter osteoclast or osteoblast function in paediatric users [27]. Moreover, no significant differences were observed in BMD among postmenopausal women using acid suppressants (PPIs and H2RA), while in men, even lower cross-sectional bone masses were observed
[28]. In addition, the most recent study performed by Targownik et al. [29] showed that both chronic PPI use and high daily doses of PPIs were not associated with osteoporosis or accelerated BMD loss.

Several observational studies that investigated the association between duration of acid suppressant use and fracture risk found discrepant results as well [8, 10-12]. Both Yang et al. and Targownik et al. [8, 10] found that fracture risk increased with longer durations of PPI use. In contrast, members of our group found results which are

Table 4 Use of PPIs or H2RAs and risk of hip fracture, by exposure to oral corticosteroids

\begin{tabular}{|c|c|c|c|c|c|c|}
\hline & Cases $(n=6,763)$ & $\%$ & Controls $(n=26,341)$ & $\%$ & Crude OR (95\% CI) & Adjusted $^{\mathrm{a}}$ OR $(95 \% \mathrm{CI})$ \\
\hline \multicolumn{7}{|l|}{ PPI use before } \\
\hline Never & 5,810 & 85.9 & 23,430 & 88.9 & 1.00 & 1.00 \\
\hline Current use & 305 & 4.5 & 773 & 2.9 & $1.62(1.41-1.86)$ & $1.20(1.04-1.40)$ \\
\hline \multicolumn{7}{|c|}{ By oral corticosteroid use in the 6 months before ${ }^{b}$} \\
\hline Unexposed & 256 & 3.8 & 682 & 2.6 & $1.54(1.33-1.79)^{\mathrm{c}}$ & $1.19(1.02-1.40)$ \\
\hline$<7.5 \mathrm{mg} /$ day & 21 & 0.3 & 47 & 0.2 & $1.86(1.11-3.12)$ & $1.31(0.77-2.22)$ \\
\hline $7.5-15 \mathrm{mg} /$ day & 12 & 0.2 & 20 & 0.1 & $2.51(1.21-5.18)$ & $1.91(0.90-4.07)$ \\
\hline$\geq 15 \mathrm{mg} /$ day & 13 & 0.2 & 14 & 0.1 & $3.67(1.72-7.84)^{\mathrm{c}}$ & $2.35(1.07-5.20)$ \\
\hline \multicolumn{7}{|l|}{ H2RA use before } \\
\hline Never & 5,624 & 83.2 & 22,545 & 85.6 & 1.00 & 1.00 \\
\hline Current use & 196 & 2.9 & 520 & 2.0 & $1.52(1.28-1.80)$ & $1.19(1.00-1.42)$ \\
\hline \multicolumn{7}{|c|}{ By oral corticosteroid use in the 6 months before ${ }^{b}$} \\
\hline Unexposed & 165 & 2.4 & 468 & 1.8 & $1.42(1.19-1.71)$ & $1.18(0.98-1.43)$ \\
\hline$<7.5 \mathrm{mg} /$ day & 16 & 0.2 & 24 & 0.1 & $2.64(1.39-4.99)$ & $1.73(0.90-3.35)$ \\
\hline $7.5-15 \mathrm{mg} /$ day & 9 & 0.1 & 16 & 0.1 & $2.29(1.01-5.19)$ & $1.43(0.61-3.38)$ \\
\hline$\geq 15 \mathrm{mg} /$ day & 5 & 0.1 & 6 & 0.0 & $3.59(1.09-11.78)$ & $2.34(0.68-8.06)$ \\
\hline
\end{tabular}

$O R$ odds ratio, $C I$ confidence interval

${ }^{\text {a }}$ Adjusted for same confounders listed in Table 2

${ }^{\mathrm{c}}$ Corticosteroids by prednisolone equivalents; data not shown for patients with only 1 oral steroid dispensing before the index date

${ }^{\mathrm{d}}$ Wald statistic: the risk of hip fracture is statistically significantly higher among PPI users exposed to corticosteroids $\geq 15$ mg/day compared with PPI users unexposed to corticosteroids $(P<0.05)$ 
similar to the present study (i.e. PPI use for a duration $\leq 1$ year is associated with the highest fracture risk) using the same database as Yang et al. [11]. Moreover, our sensitivity analysis, in which we resembled the definitions of Yang et al., did not support a duration-of-use effect. Additionally, Kaye et al. [12] who also used the GPRD database did not find any association between the number of PPI prescriptions and hip fracture. The reasons for these discrepancies remain unclear.

There are alternative explanations for the small, overall 1.2-fold increased risk among current users of acid suppressants. These include the inability of the current and previous studies, to measure (or only partially measure) alcohol consumption, smoking history and low body mass index. All these factors are associated with an increased risk of fracture [30-32]. Besides, PPIs are often used for the eradication of Helicobacter pylori [33], which may be associated with an increased risk of osteoporosis [34]. In addition, PPIs are associated with the onset of Clostridium difficile [35], which may be an alternative explanation for the increased risk of fracture. Finally, celiac disease, which is associated with the onset of reflux oesophagitis [36], has recently been associated with an increased risk of both osteoporosis and fracture [37]. Nevertheless, we were unable to fully adjust for these three potential confounders, because PHARMO RLS has missing data of diagnoses determined outside the hospital.

Our study has several strengths. As we used a population-based design, our study represents the entire population of the Netherlands. It has a large study size and the average period of follow-up exceeded 4 years. Furthermore, written dosage instructions allowed us to discriminate between different average daily doses of PPIs and H2RAs and concomitant use of average daily dosages of oral glucocorticoids. The main limitation of our study is the inability to adjust for residual confounding. No information was present in the PHARMO RLS about low body mass index, alcohol consumption, smoking, celiac disease, $C$. difficile and $H$. pylori eradication. These potential confounders could have overestimated the observed increased fracture risk. Conversely, no information was present about the use of over-the-counter drugs like calcium and vitamin D supplements, which decrease this risk [4, 38]. Yet, according to our knowledge, the trend observed in the spline showing the recency of use (Fig. 1) would be similar, even after adjustments for these potential confounders. In addition, although not confirmed by clinical trials, current literature suggests that non-steroidal anti-inflammatory drugs inhibit bone formation [39]. For this reason, our analyses were adjusted for the use of these drugs in the 6 months before the index date. Finally, data collection for this study ended on the 31 st of December 2002. Addition of more recent data would probably identify more long-term
PPI users, which would add more power to the duration of use results.

In conclusion, our findings show that there is probably no causal relationship between PPI use and hip fracture risk. The observed association may be the result of unmeasured distortions: although current use of PPIs was associated with a 1.2-fold increased risk of hip/femur fracture, the positive association was attenuated with longer durations of continuous use. Our findings do not support that discontinuation of PPIs decreases risk of hip fracture in elderly patients.

Acknowledgement This work was funded in part by NIHR, Biomedical Research Unit in Musculoskeletal Sciences, Nuffield Orthopaedic Centre, Oxford.

Conflicts of interest The Division of Pharmacoepidemiology and Pharmacotherapy, Utrecht Institute for Pharmaceutical Sciences, employing authors Sander Pouwels, Arief Lalmohamed, Patrick Souverein, Hubert GM Leufkens, Anthonius de Boer, Tjeerd-Pieter van Staa and Frank de Vries, has received unrestricted funding for pharmacoepidemiological research from GlaxoSmithKline, Novo Nordisk, private-public funded Top Institute Pharma (www. tipharma.nl and includes cofunding from universities, government, and industry), the Dutch Medicines Evaluation Board and the Dutch Ministry of Health. GPRD, employing authors Tjeerd-Pieter van Staa and Frank de Vries, is owned by the UK Department of Health and operates within the Medicines and Healthcare products Regulatory Agency (MHRA). GPRD is funded by the MHRA, Medical Research Council, various universities, contract research organisations and pharmaceutical companies. The views expressed in this paper are those of the authors and do not reflect the official policy or position of the Medicines and Healthcare products Regulatory Agency, UK. Professor Cyrus Cooper has undertaken consultancy and lecturing commitments for Alliance for Better Bone Health, Eli Lilly, Novartis, GSK Roche, Servier, MSD, Amgen.

Open Access This article is distributed under the terms of the Creative Commons Attribution Noncommercial License which permits any noncommercial use, distribution, and reproduction in any medium, provided the original author(s) and source are credited.

\section{References}

1. Richter JE (2007) Gastrooesophageal reflux disease. Best Pract Res Clin Gastroenterol 21:609-631

2. O'Connell MB, Madden DM, Murray AM et al (2005) Effects of proton pump inhibitors on calcium carbonate absorption in women: a randomized crossover trial. Am J Med 118:778-781

3. Graziani G, Badalamenti S, Como G et al (2002) Calcium and phosphate plasma levels in dialysis patients after dietary Ca-P overload. Nephron 91:474-479

4. Ensrud KE, Duong T, Cauley JA et al (2000) Low fractional calcium absorption increases the risk for hip fracture in women with low calcium intake. Study of Osteoporotic Fractures Research Group. Ann Intern Med 132:345-353

5. Mizunashi K, Furukawa Y, Katano K et al (1993) Effect of omeprazole, an inhibitor of $\mathrm{H}+, \mathrm{K}(+)$-ATPase, on bone resorption in humans. Calcif Tissue Int 53:21-25 
6. Rzeszutek K, Sarraf F, Davies JE (2003) Proton pump inhibitors control osteoclastic resorption of calcium phosphate implants and stimulate increased local reparative bone growth. J Craniofac Surg 14:301-307

7. Tuukkanen J, Väänänen HK (1986) Omeprazole, a specific inhibitor of $\mathrm{H}+-\mathrm{K}+-$ ATPase, inhibits bone resorption in vitro. Calcif Tissue Int 38:123-125

8. Yang YX, Lewis JD, Epstein S et al (2006) Long-term proton pump inhibitor therapy and risk of hip fracture. JAMA 296:29472953

9. Vestergaard P, Rejnmark L, Mosekilde L (2006) Proton pump inhibitors, histamine $\mathrm{H} 2$ receptor antagonists, and other antacid medications and the risk of fracture. Calcif Tissue Int 79:76-83

10. Targownik LE, Lix LM, Metge CJ et al (2008) Use of proton pump inhibitors and the risk of osteoporosis-related fractures. CMAJ 179:319-326

11. de Vries F, Cooper AL, Cockle SM et al (2009) Fracture risk in patients receiving acid-suppressant medication alone and in combination with bisphosphonates. Osteoporos Int 20:1989-1998

12. Kaye JA, Jick H (2008) Proton pump inhibitor use and risk of hip fractures in patients without major risk factors. Pharmacotherapy 28:951-959

13. Heerdink ER, Leufkens HG, Herings RM et al (1998) NSAIDs associated with increased risk of congestive heart failure in elderly patients taking diuretics. Arch Intern Med 158:1108-1112

14. Herings R (1993) The PHARMO Drug Data Base: design and structure. PHARMO, a record linkage system for post-marketing surveillance of prescription drugs in the Netherlands. Doctoral thesis. Utrecht University, Utrecht, the Netherlands, pp 17-32

15. Herings RM, Stricker BH, de Boer A et al (1995) Benzodiazepines and the risk of falling leading to femur fractures. Dosage more important than elimination half-life. Arch Intern Med 155:1801-1807

16. Norwegian Institute of Public Health. WHO International Working Group for drug statistics methodology. 2009; Available at http://www.whocc.no/atcddd/

17. van Staa TP, Leufkens HG, Abenhalm L et al (2000) Use of oral corticosteroids and risk of fractures. J Bone Miner Res 15:993-1000

18. Laan RF, van Riel PL, van de Putte LB et al (1993) Low-dose prednisone induces rapid reversible axial bone loss in patients with rheumatoid arthritis. A randomized, controlled study. Ann Intern Med 119:963-968

19. Greenland S (1995) Dose-response and trend analysis in epidemiology: alternatives to categorical analysis. Epidemiology 6:356-365

20. Hoogerwerf W, Pasricha P (2001) Agents used for control of gastric acidity and treatment of ulcers and gastroesophageal reflux disease. In: Goodman \& Gilman's. The pharmacological basis of therapeutics. The McGraw-Hill Companies, Inc, United States of America, pp 1005-1020

21. Insogna KL (2009) The effect of proton pump-inhibiting drugs on mineral metabolism. Am J Gastroenterol 104(2 Suppl):S2-S4
22. Hardy P, Sechet A, Hottelart C et al (1998) Inhibition of gastric secretion by omeprazole and efficiency of calcium carbonate on the control of hyperphosphatemia in patients on chronic hemodialysis. Artif Organs 22:569-573

23. Recker RR (1985) Calcium absorption and achlorhydria. N Engl J Med 313:70-73

24. Serfaty-Lacrosniere C, Wood RJ, Voytko D et al (1995) Hypochlorhydria from short-term omeprazole treatment does not inhibit intestinal absorption of calcium, phosphorus, magnesium or zinc from food in humans. J Am Coll Nutr 14:364-368

25. Knox TA, Kassarjian Z, Dawson-Hughes B et al (1991) Calcium absorption in elderly subjects on high- and low-fiber diets: effect of gastric acidity. Am J Clin Nutr 53:1480-1486

26. Ivanovich P, Fellows H, Rich C (1967) The absorption of calcium carbonate. Ann Intern Med 66:917-923

27. Kocsis I, Arato A, Bodanszky H et al (2002) Short-term omeprazole treatment does not influence biochemical parameters of bone turnover in children. Calcif Tissue Int 71:129-132

28. Yu EW, Blackwell T, Ensrud KE et al (2008) Acid-suppressive medications and risk of bone loss and fracture in older adults. Calcif Tissue Int 83:251-259

29. Targownik LE, Lix LM, Leung S et al (2009) Proton pump inhibitor use is not associated with osteoporosis or accelerated bone mineral density loss. Gastroenterology 138:896-904

30. Cumming RG, Nevitt MC, Cummings SR (1997) Epidemiology of hip fractures. Epidemiol Rev 19:244-257

31. De Laet C, Kanis JA, Odén A et al (2005) Body mass index as a predictor of fracture risk: a meta-analysis. Osteoporos Int 16:1330-1338

32. Kanis JA, Johnell O, Oden A et al (2005) Smoking and fracture risk: a meta-analysis. Osteoporos Int 16:155-162

33. Sachs G, Wen Y, Scott DR (2009) Gastric infection by Helicobacter pylori. Curr Gastroenterol Rep 11:455-461

34. Figura N, Gennari L, Merlotti D et al (2005) Prevalence of Helicobacter pylori infection in male patients with osteoporosis and controls. Dig Dis Sci 50:847-852

35. van Staa TP, de Vries F, Leufkens HG (2006) Gastric acidsuppressive agents and risk of Clostridium difficile-associated disease. JAMA 295:2599

36. Cuomo A, Romano M, Rocco A et al (2003) Reflux oesophagitis in adult celiac disease: beneficial effect of a gluten-free diet. Gut 52:514-517

37. Agardh D, Björck S, Agardh CD et al (2009) Coeliac diseasespecific tissue transglutaminase autoantibodies are associated with osteoporosis and related fractures in middle-aged women. Scand J Gastroenterol 44:571-578

38. Jackson C, Gaugris S, Sen SS et al (2007) The effect of cholecalciferol (vitamin D3) on the risk of fall and fracture: a meta-analysis. QJM 100:185-192

39. Vuolteenaho K, Moilanen T, Moilanen E (2008) Non-steroidal anti-inflammatory drugs, cyclooxygenase- 2 and the bone healing process. Basic Clin Pharmacol Toxicol 102:10-14 